Please do not remove this page

RMIT

UNIVERSITY

\title{
The physical and emotional threads of the archetypal hero's journey: Proposing common terminology and re-examining the narrative model
}

Batty, Craig

https://researchrepository.rmit.edu.au/esploro/outputs/9921858138301341/filesAndLinks?institution=61RMIT_INST\&index=null

Batty, C. (2010). The physical and emotional threads of the archetypal hero's journey: Proposing common terminology and re-examining the narrative model. Journal of Screenwriting, 1(2), 291-308.

https://doi.org/10.1386/josc.1.2.291/1

Document Version: Accepted Manuscript

Published Version: https://doi.org/10.1386/josc.1.2.291/1

Repository homepage: https://researchrepository.rmit.edu.au

(C) 2012 Intellect

Downloaded On 2023/04/26 19:41:22 +1000

Please do not remove this page 
Thank you for downloading this document from the RMIT Research Repository.

The RMIT Research Repository is an open access database showcasing the research outputs of RMIT University researchers.

RMIT Research Repository: http://researchbank.rmit.edu.au/

\section{Citation:}

Batty, C 2010, 'The physical and emotional threads of the archetypal hero's journey: Proposing common terminology and re-examining the narrative model', Journal of Screenwriting, vol. 1, no. 2, pp. 291-308.

See this record in the RMIT Research Repository at: http://researchbank.rmit.edu.au/view/rmit:18651

Version: Accepted Manuscript

Copyright Statement: (c) 2012 Intellect

Link to Published Version:

http://dx.doi.org/10.1386/josc.1.2.291/1 


\title{
The physical and emotional threads of the archetypal hero's journey: proposing common terminology and re-examining the narrative model
}

\author{
Craig Batty \\ The Media School, Bournemouth University
}

\begin{abstract}
This article will discuss how, in mainstream film screenplays, the protagonist undergoes both an actual, physical journey and an internal, emotional journey, pulled together by the invisible hand of the screenwriter in order to create the complete narrative experience. Central to the article is an evaluation of how character transformation (arc) is positioned against physical action (plot), arguing that the two can be mapped out as individual yet symbiotic threads of a narrative: the physical and the emotional journeys.

After mapping the territory of what is already written on this subject, the works of Joseph Campbell and his 'protégé' Christopher Vogler (Clayton 2007: 210) will be drawn together to offer a re-examination of the model of the Hero's Journey. Assessing these two narrative threads (physical and emotional) as both distinct and symbiotic, it will be clear that a special relationship exists between plot and character, where character transformation is encouraged to take place within the frame of the physical action of the plot. The substance of such a transformation, the emotional core of the narrative experience, is what lives on in the audience, 'post-text'; the physical action of a film story may frame emotion, but emotion has the power to break the frame and take on a life of its own.
\end{abstract}

\section{Keywords}

character arc, emotional journey, narrative, physical journey, story, structure

\section{Introduction}

The notion of the character journey is no stranger to those whose interests are in screenwriting. The numerous 'how to' texts on the current market, such as Robert McKee (1999), Syd Field (2003), Linda Aronson (2001) and Charlie Moritz (2001), use the term 
and its variants (character arc, hero's journey) to suggest it is an important component to most screenplays. Even by its very name, Christopher Vogler's The Writer's Journey: Mythic Structure for Storytellers and Screenwriters (1999), a text based upon Joseph Campbell's monomyth of the Hero's Journey, gives us a strong sense that character movement from one place to another - the journey - is essential to the fabric of a screenplay. Patrick Cattrysse's article 'The Protagonist's Dramatic Goals, Wants and Needs' in the inaugural issue of the Journal of Screenwriting (2009: 83-97) points to such debates (though Cattrysse considers the result of the journey, not the journey itself), telling us that the craft of character development is of specific interest in both creative and academic circles.

What I want to explore in this article, as an addendum to the aforementioned work, is how this journey can be understood as combining both a literal, physical journey (the plot), and a more abstract, emotional character journey (the story), two elements brought together by the screenwriter to create the complete narrative experience. McKee (1999: 4) tells us that 'the archetypal story unearths a universally human experience, then wraps itself inside a unique, culture-specific expression', suggesting that the underlying theme or meaning of a screenplay is one of human connection and emotion. McKee's point is that what makes one screenplay different from another is the way this theme or meaning is presented. Therefore, it is my intent to explore how a screenplay narrative employs a specific structure of plot to unearth what is essentially a shared, universal story, two narrative threads working for one overall narrative experience.

As it currently stands, most screenwriting literature ('how to' texts, professional articles, etc.) either simplifies the journey into one all-embracing model that stands for both physical action and character emotion, or acknowledges two threads (journeys) to a narrative but in an inconsistent, under-explored and sometimes confusing way. The paradox here is between what I would call 'slippery writing' from the 'how to' market and 'controlled writing' from the academic market, and is perhaps a way by which we can see why such a problem in understanding the subject has arisen. For example, 'how to' texts rarely reference their predecessors, therefore not actually developing an argument but merely giving another viewpoint, and are often not written with as much precision and detailed syntactical thought as academic texts. As will be detailed later, this sometimes 
makes 'how to' books slightly confusing because arguments can shift and change as the text progresses, but with no real acknowledgement that this is what is happening; different terminologies, for example, will be used sporadically. Academic texts, on the other hand, tend to go through a much more rigorous review and revision process, therefore the writing feels tighter and less susceptible to flaws such as changing use of terminology. Furthermore, as Cattrysse outlines, although screenwriting manuals and academic narrative studies both deal with issues of storytelling, they have managed to largely ignore each other: 'From a practitioner's point of view, academic jargon is often considered too sophisticated and not practical. From an academic's point of view, the practitioner's terminology is considered imprecise and confusing' (Cattrysse 2009: 84). Therefore, most academic literature has refused to address its audience in a practical way, not offering tools and techniques that can be used to shape the writing of a screenplay. Similarly, most screenwriting literature has refused to address its audience in a critically informed way, offering, for example, a lack of awareness of what other texts have come before and that the knowledge being offered is developmental from others' ideas. ${ }^{i}$ In order to partly remedy this problem, then, this article will outline some of the key writings available on protagonist journeys, and, by bringing them together in a creative-critical space, offer a more precise, controlled understanding of the subject which only then can be rightfully proposed $^{\mathrm{ii}}$ as a re-examined, enhanced model of the Hero's Journey that may be useful for screenwriters. In this way, it is hoped that an interlingua 'sophisticated enough to meet academic standards of precision, but not so sophisticated as to appear pedantic to the practice-oriented writer or trainer' will be achieved, one which merges together 'the overspecialized academic and the imprecise practitioner' (Cattrysse 2009: 84-85).

\section{Mapping the territory so far}

For Aristotle, in his Poetics, action is the primary element of drama; characters should act out their personalities, beliefs and states-of-mind, not simply recall them through dialogue. Furthermore, action should be manifested into a 'series of events which constitutes a wellformed plot [that] is therefore closed at both ends, and connected in between' (Aristotle 1996: xxiii). In other words, it should have a beginning, middle and end, the events in between following from one another to trace the journey of the character from start to 
finish. What needs to be questioned further is the extent to which Aristotle actually argues that plot (action) is primary, and character (emotion) secondary. He writes that '[w]ellbeing and ill-being reside in action, and the goal of life is an activity, not a quality' (Aristotle 1996: 11). Although 'action', 'goal' and 'activity' purvey importance upon the sense of plot physicality, we can see that 'well-being' and 'ill-being' describe someone's state within a given situation, not the situation itself. Identifying that characters 'achieve well-being or its opposite on the basis of how they fare' (Aristotle 1996: 11) does indeed infer a link between the external, physical plot (how they fare) and the internal, emotional plot (well- or ill-being).

For Lajos Egri, whose book The Art of Dramatic Writing was originally published in 1942:

It is not enough, in your study of a man, to know if he is rude, polite, religious, atheistic, moral, degenerate. You must know why. We want to know why man is as he is, why his character is constantly changing, and why it must change whether he wishes it or not. (Egri 2004: 34)

Egri reinforces the importance of understanding how and why characters change internally, and how this relates to action. In other words, the fabric of character is intrinsically linked to the fabric of plot. He posits that '[a]ll emotion has physical effects' (Egri 2004: 41); in other words, what drives a character from within is evident in the physical world he makes for himself. The nature of character development requires a character to be in constant change, and so for Egri, '[t]he smallest disturbance of his well-ordered life will ruffle his placidity and create a mental upheaval, just as a stone which slides through the surface of a pond will create far-reaching rings of motion' (Egri 2004: 47). If the sliding stone is the essence of an emotional character change, then perhaps the rings can be considered the plot, formed as a reaction to his actions which themselves are driven by emotion. Egri advises that a writer should not fabricate situations for his character but allow his character to shape the plot: 'we do not find it hard to think of situations. The situations are inherent in the character' (Egri 2004: 94, emphasis in original). Or, as an analogy:

What would the reader think of us if we were to announce that, after long and arduous study, we had come to the conclusion that honey is beneficial to 
mankind, but that the bee's importance is secondary, and that the bee is therefore subsidiary to its product? (Egri 2004: 103)

For Joseph Campbell in The Hero with a Thousand Faces, myth is at the centre of the human experience; a way of living, feeling, knowing. Campbell posits that myth is like an 'opening' through which humans not only understand life, but understand how to live it. This 'ring of myth', the essential force behind human action, can be understood as character growth (story); the underlying theme of a given narrative, existing 'beneath its varieties of costume' (Campbell 1993: 4). Campbell believes that although the surface may present itself in a multitude of ways, the subterrain is always universal:

[t]he unconscious sends all sorts of vapours, odd beings, terrors, and deluding images up into the mind - whether in dream, broad daylight, or insanity; for the human kingdom, beneath the floor of the comparatively neat little dwelling that we call our consciousness, goes down into unsuspected Aladdin caves. (Campbell 1993: 8)

Campbell, in his work on the importance of myth in various cultures, references Freud and psychoanalysis; as screenwriters we can adopt and adapt Campbell's ideas and intuit that a protagonist in a screenplay may be like a dreamer in a psychoanalyst's chair. Both undergo a journey of emotional development alongside a journey of physical action, and it is precisely the combination of the two that leads to an emotional transformation. If '[d]ream is the personalized myth, myth the depersonalized dream' (Campbell 1993: 19), then dream is the physical journey, the subject-specific plot that a protagonist follows, and myth is the emotional journey, the underlying universal story to that plot which appeals and speaks to the audience.

Christopher Vogler, using Campbell's work as his base, asserts that:

The pattern of the Hero's Journey is universal, occurring in every culture, in every time. It is as infinitely varied as the human race itself and yet its basic form remains constant [...] Stories built upon the model of the Hero's Journey have an appeal that can be felt by everyone, because they well up from a universal source in the shared unconscious and reflect universal concerns. (Vogler 1999: 10-11) 
It is clear that storytelling can be regarded as both specific and generic, that stories are told in different ways, with varying characters, plot situations and story worlds, yet at heart they are all the same because each promotes a connection between hero and audience; art and life; fiction and fact. Developing Campbell's model of the Hero's Journey for screenwriters, Vogler notes:

It may be an outward journey to an actual place: a labyrinth, forest or cave, a strange city or country, a new locale that becomes the arena for her conflict with antagonistic, challenging forces.

But there are as many stories that take the hero on an inward journey, one of the mind, the heart, and the spirit. In any good story the hero grows and changes, making a journey from one way of being to the next: from despair to hope, weakness to strength, folly to wisdom, love to hate, and back again. (Vogler 1999: 13)

Vogler's work posits that the journey of a screenplay can be an outward, physical one or an inward, personal one, suggesting that either type has the potential to work, and moreover, that the two do not have to work together. However, Vogler's assertion 'In any good story the hero grows and changes' becomes confusing because it is not clear whether he is referring solely to a screenplay that takes the 'inward' approach, or whether the hero must grow and change in 'outward journey' screenplays. From this we can see that perhaps there is an inconsistency in clarity in Vogler's work, making it vulnerable to critique; or, worse, detrimental to writing practice. It is only much later in his book that Vogler clearly articulates what he actually advocates about the protagonist's narrative journey: '[e]very hero needs both an inner and an outer problem' (Vogler 1999: 87); furthermore, '[c]haracters without inner challenges seem flat and uninvolving, however heroically they may act. They need an inner problem, a personality flaw or a moral dilemma to work out. They need to learn something in the course of the story’ (Vogler 1999: 88).

Robert McKee argues that a screenwriter cannot look at character and structure as separate entities because 'structure is character. Character is structure’ (McKee 1999: 100, emphasis in original). For McKee, neither character nor structure is more important than the other (McKee 1999: 100), and the true nature of character is revealed by choices that are made and then acted out: 'As he chooses, he is' (McKee 1999: 101). McKee uses a 
summary of Hamlet to demonstrate how character and structure work together to form the character arc, suggesting that a successful screenplay lies in the writer's ability to create a narrative which progressively follows a character's plight through action and emotion, and which by the resolution demonstrates a fundamental change in the character's inner being. What is perhaps most important for the screenwriter when considering the dualistic nature of a protagonist's journey is the statement that:

Structure and character are interlocked. The event structure of a story is created out of the choices that characters make under pressure and the actions they choose to take, while characters are the creatures who are revealed and changed by how they choose to act under pressure. If you change one, you change the other. (McKee 1999: 106)

Linda Aronson, whose book Screenwriting Updated focuses on the study of alternative narrative structures, specifically explores this idea that screenplays are comprised of two narrative threads; one thread features the internality of character and the other features the externality of plot. Together, they create a complete narrative. The terms 'action line' and 'relationship line' (Aronson 2001: 55-104) are presented on the grounds that they clearly embody the external (plot-driven) and internal (character-driven) components of the narrative. Aronson (2001: 54) argues that 'in many films the main plot or action line only exists to permit the relationship line (or subplot, or background plot) to happen', indicating that whatever the physical battle taking place on screen, it is really the character's internal development that is important. I would, however, question the use of the word 'only' here, because it could negate the importance needed to carefully construct plot events that work to tease out the underlying story. It may be that the key to drama is what happens internally, but the way that the events are structured to bring about this internality should not be seen as secondary. As with Vogler's shifting levels of advice, though, Aronson does later clarify that:

The relationship line will not work properly unless it is pulled along by a strong action line, that is, a scenario that not only forces the relationship line characters together but keeps challenging them individually and incrementally in different ways. (Aronson 2001: 56, emphasis in original) 
Thus, a screenplay, according to Aronson, must interweave both the action line and the relationship line, and 'every incident in the action line must be chosen, not only for its relevance to the story told in the action line, but for its capacity to take the relationship line another step forward' (Aronson 2001: 56). Laurie Hutzler, an American script consultant who specializes in the emotional content of stories, writes:

The greatest challenge and art of storytelling is to reveal the universal in the personal. The most powerful stories depict an individual culture, society or community with all of its idiosyncrasies, distinctiveness and peculiarities described in rich and truthful detail. Then, within that narrow setting or milieu, these stories go on to explore the universal human emotions at work within the lives of characters. (Hutzler 2005: 6)

It is possible to read from this advice that a story-defined plot operates within a specific story world and emotion is the universal quality that appeals to audiences across the globe, crossing 'time, distance, culture, class, language, religion and politics' (Hutzler 2005: 6). Emotion and physical action operate within the same context but possess different functions, as Hutzler (2005: 6) writes: 'Order or structure is a principle of organization that pulls us through a story from beginning to end but it is our emotional experience that makes a film memorable.' This ties in neatly with Campbell's discussions of psychoanalysis, where recounting a dream's 'plot' to the doctor enables an unearthing of subsurface meaning, and a subsequent possibility of leading the patient to a more healthy state of being. To turn these ideas back on themselves, however, Hutzler (2005: 8) writes that: 'You can only reach the universal through the personal.' The re-focus of attention here, that the inner journey of a character needs to be framed by an outer journey of plot, reminds us (like Aronson above) that the only way to bring about emotional transformation of character is by the use of physical action. With this in mind, Hutzler brings back the terms 'want' and 'need' as useful prompts: 'What does your character want: what is their concrete physical objective in the story? What does your character need: what is the deeper human longing that they ignore, deny or suppress [...]?' (Hutzler 2005: 7). Here, then, we can see that 'want' clearly relates to the outer, plot-centred thread of a screenplay; and 'need' to the inner, emotion-centred thread; together they explore both the personal and the universal, and create the complete narrative experience of a screenplay. 


\section{Defining new terms}

From these texts, it is evident that a praxis exists whereby the screenplay protagonist undertakes two journeys that function as individual yet interwoven threads of a complete narrative. The question is - how do we define these journeys? It would be easy to accept Aronson's terminology of 'action line' and 'relationship line' for not only are the ideas of all the authors discussed, they clearly denote the external and the internal, and purvey a sense of movement - the journeys taken. However, although 'action line' captures the idea of characters physically acting, reacting and externalizing choices, it possesses possible signification to action-based films: chases, fights, explosions, etc. Similarly, 'relationship line' has possible connotations with love and romance, and although many films operate on a romantic level, this part of the story is not always what is meant by the relationship line; it is more about the personal journey undertaken, whether that involves love or not.

Throughout the texts discussed, the words 'physical' and 'emotional' are used in various ways. Hutzler, for example, uses them in relation to 'want' and 'need', telling us that the narrative threads relate to journeys that are physical and emotional. One of the first screenwriting gurus, American Syd Field, writes that '[t]here are two kinds of action physical action and emotional action' (Field 2003: 29, emphasis in original). Although his delineation of the words is useful, that '[p]hysical action is holding up a bank [...] a car chase [...] a race or competition [...] Emotional action is what happens inside your characters during the story' (Field 2003: 29), the term 'emotional action’ here may not be so useful. Calling the emotional thread of the narrative 'emotional action' may be an oxymoron: one may wonder if emotion can ever be an action, or merely the cause or consequence of an action? However, the adjectives themselves, 'physical' and 'emotional', are useful for the screenwriter, more so I believe than Aronson's 'action' and 'relationship', for the reasons given above. I therefore would like to posit the terms 'physical journey' and 'emotional journey' in developing an understanding of the duality of a screenplay narrative. 'Physical journey' is more useful than 'action line' because of its non-signification to genre; 'emotional journey' is more useful than 'relationship line' because of its relation to character drive, not theme or genre. The word 'journey' is used for both to give a sense of progression; a ‘journey’ moves and creates change, not static like a 'line’. Although this 
might seem like a pedantic view of others' semantics, my aim here is to call for common terminology that will help us to understand what the 'gurus' are writing about, and move forward our level of film narrative analysis so that we can enhance writing practice.

This terminology adds nothing to practice nor means anything in theory, however, unless it can be mapped onto a screenplay narrative pattern in order to understand exactly how the two journeys take shape. What is required is a separation of the physical and emotional journeys, detailing how each develops individually and symbiotically over the course of the screenplay. Although Vogler (1999: 212) and screenwriters' guide Stuart Voytilla (1999: 7) suggest that the emotional journey (character arc) can be mapped alongside the physical journey (plot) in a narrative, neither offers a specific way of doing this nor examples to illustrate. I am therefore suggesting that to fully understand the relationship between a protagonist's physical and emotional journey, more attention must be paid to:

- Individual narrative stages

- The way in which, both physically and emotionally, the stages work for the whole

Vogler's twelve-stage model of the Hero's Journey offered in The Writer's Journey, an interpretation of Campbell's seventeen-stage model offered in The Hero with a Thousand Faces, will, in fuller extrapolation, be used to achieve this mapping. Voytilla (1999: 3) suggests that writers should 'consider the Hero's Journey [model] as a writing tool, an extremely malleable paradigm, that expands your intellectual and creative thinking, opening you to new avenues of exploration'. Its use here in uncovering the physical and emotional journeys of a protagonist is also that of a writing tool, not an exact method of working, or worse, a paradigm to be replicated without creativity. By bringing together Campbell and Vogler in one space, and addressing a desire to fully identify the two narrative threads of a screenplay, my re-examined model of the Hero's Journey is meant to inspire, not to inhibit; after all, 'each [screenplay] is a unique story, integrating the Hero’s Journey tools to support its character and story needs’ (Voytilla 1999: 294), not dictate them in an unyielding way. Although British screenwriter and lecturer Sue Clayton has a practical reason to be sceptical about such narrative 'modelling', namely that 'the exponents of the universal hero's journey' have in some ways 'limited the creative 
possibilities of working with myths, not by constraining their manifest content, but by limiting their form of address in the context of prescribing narrative structure' (Clayton 2007: 221), this is arguable. The Hero's Journey is adaptable to non-traditional forms of storytelling (see, for example, Aronson 2001; Batty and Waldeback 2008), and can be readily used in whatever way appropriate to the screenwriter. In fact, as Clayton outlines with reference to her screenwriting work, 'mythic material itself becomes continually new by being reused in different contexts and alongside other sources' (Clayton 2007: 221).

Vogler’s mapping of the Hero's Journey (1999: 12) incorporates the variations of his and Campbell's work, placing them together on paper to show their differences and similarities:

Christopher Vogler:

The Writer's Journey

Act One

Ordinary World

Call to Adventure

Refusal of the Call

Meeting with the Mentor

Crossing the First Threshold

Act Two

Tests, Allies, Enemies

Approach to the Inmost Cave

Ordeal

Reward

Act Three

The Road Back
Joseph Campbell:

The Hero with a Thousand Faces

Departure, Separation

World of Common Day

Call to Adventure

Refusal of the Call

Supernatural Aid

Crossing the First Threshold

Belly of the Whale

Descent, Initiation, Penetration

Road of Trials

Meeting with the Goddess

Woman as Temptress

Atonement with the Father

Apotheosis

The Ultimate Boon

\section{Return}

Refusal of the Return

The Magic Flight 
Rescue from Within

Crossing the Threshold

Return

Resurrection

Master of the Two Worlds

Return with Elixir

Freedom to Live

\section{Proposing an enhanced model for screenwriters}

What follows is an enhanced and expanded version of an existing successful model that may offer new inspirations and new insights into understanding the protagonist's journey. The length of this article does not permit all the methods of arriving at this model to be presented, ${ }^{\text {iii }}$ but to briefly outline; both The Writer's Journey and The Hero with a Thousand Faces are mapped against each other in terms of their narrative stages, the former being generally more useful for a practical application of ideas, the latter for an intellectual appreciation of ideas. Then, a detailed reading of each stage as written by Vogler and Campbell is undertaken in order to extract the essential narrative components that each holds, bringing together the practical and the intellectual to identify as much as possible about the physical and the emotional. Following this, the essential narrative components (as key words) are brought together and then separated into physical and emotional traits so that a concise guide to each stage is created. Finally, the supplementary stages of Campbell's model are incorporated into the twelve stages offered by Vogler, the reason being to create one complete 'new' model that is comprised of both authors' views simultaneously in each stage. ${ }^{\text {iv }}$ Care has been taken in developing the model to propose a strong sense of universal ideas and concepts as opposed to specific content. Although examples can be useful, they may also be constraining and sometimes limit one's understanding of an idea. The specific intention here is to strip a narrative back to its most basic, 'mythical' elements; a framework for developing the screenwriter's awareness of the physical and emotional journey of a protagonist's story, upon which a plot and character traits can later be painted. As the model thus demonstrates, there is no reference to specific instances of plot or emotion from existing films; rather, there is a deliberate attempt to keep the model content-less and genre-less in order that it can be applied creatively (not as a set template) to any given screenplay. 


\section{The Hero's Journey, re-examined}

Bringing together Campbell and Vogler, then, fuelled by a greater understanding of the physical and emotional narrative threads of a screenplay as evidenced above, my reexamined model of the Hero's Journey is offered as such:

\section{Ordinary World / Limited Awareness of a Problem}

Physically, the protagonist is located in an Ordinary World, a place where he goes about his ordinary business and experiences familiar concepts, ideals, routines and patterns of living. Negative associations are made between the protagonist and his physical world; he may be trapped by rules, regulations or people. A physical goal related to this negative situation is explicitly stated or implicitly hinted at, which raises the central plot-related question of the screenplay: his physical want.

An opening image or line of dialogue may be used as a symbol of what lies ahead in the Special World; that is, a world physically different from the Ordinary World. A visual sequence or voiceover may also be used as a prologue to the screenplay, physically highlighting elements of the protagonist's back story that will later be seen in stark contrast. Essentially, this stage sets up a baseline physical comparison between the Ordinary World and the Special World, not only showing their differences but also highlighting the different ways that the protagonist acts within them.

Emotionally, the protagonist experiences negative feelings towards familiar patterns of living. He feels that he no longer belongs in a drab, exhausted place, emotionally trapped by his surroundings. An emotional desire related to this negative situation is explicitly stated or implicitly hinted at, raising the central emotion-related question of the screenplay: his emotional need. This need has a universal fabric; it can apply to anyone, in any situation.

If a visual sequence or voiceover is used, it highlights the protagonist's emotional back story and creates a connection between him and the audience. As such, this 
stage sets up an overall baseline comparison between the protagonist's current emotional state in the Ordinary World and his transformed emotional state to come in the Special World.

\section{Call to Adventure / Increased Awareness}

Physically, an event or set of plot-related circumstances calls the protagonist to undertake a journey - a physical crossing from the Ordinary World to the Special World. That event (inciting incident) or set of circumstances, whether manifested in reality, fantasy or dream, acts as a message to the protagonist, willing him to take the steps necessary in order to leave his Ordinary World. As such, the Call to Adventure summons the protagonist away from his current existence. It is a turning point where the physicality of the Ordinary World is called into question: why stay in the familiar and exhausted when he can enter the fresh and new?

Emotionally, the event or set of circumstances draws upon the protagonist's need to transform into someone more than he currently is. The journey into a different physical domain suggests that he will become the improved, refreshed and emotionally satisfied being that he wishes to be. As such, calling the emotions of the Ordinary World into question offers the protagonist hope that his negativity will be extinguished once he enters new terrain. In essence, the protagonist's emotional need is manifested physically, where the literal journey presented gives an opportunity to aid/force his internal transformation.

\section{Refusal of the Call / Reluctance to Change}

Physically, the protagonist shows reluctance to commit to the journey called upon. Leaving the Ordinary World for promises or mere suggestions is difficult, so temporarily he holds onto the world that he knows. He expresses a deep fear of the unknown; leaving the physicality of the Ordinary World is a gamble, where new rules, regulations and people will present challenges. As such, the positive momentum of the Call is suspended, and negative attitudes about the Special World are physicalized through action and dialogue. 
Emotionally, the protagonist is torn between the two worlds, suspending the positive potential of transformation and replacing it with a negative outlook. He expresses emotional trepidation, deliberating whether to stay or go; to fail or succeed; to always wonder or actually find out. He loses the power of the affirmative, and is left with an emotional dichotomy: on the one hand, although imperfect, the Ordinary World offers safety and familiarity; on the other hand, he feels the need to absorb and integrate new forces that will refresh his emotional attitudes towards life. He may also feel the pull between selfishness and selflessness: does he remain where he is, or should he venture into new territories so that he can also restore emotion in others?

\section{Meeting with the Mentor / Overcoming Reluctance}

Physically, an actual figure, or something surfacing within the protagonist himself, appears, representing the benign, protecting power of destiny. This Mentor is required to push the protagonist past the physical blockades currently being experienced, willing him to undertake the journey called upon. The Mentor provides physical tools or weapons necessary to accomplish the journey, trains the protagonist in how to use them, and imparts crucial knowledge, advice or skill that he may require later in the story. The Mentor assures the protagonist that the support will continue throughout the journey.

Emotionally, the Mentor's protecting powers of destiny are required to challenge as well as push the protagonist past the emotional blockades currently being experienced. Emotional tools necessary to accomplish the journey are provided by the Mentor, who also guides, teaches and imparts knowledge that will support his emotional development throughout the journey. Wisdom is offered as a form of

protection, and because the Mentor may have experienced a similar journey himself in the past, advice or reassurance encourages the protagonist to go forth and enter the Special World. The Mentor also assures him that his emotional well-being will be supported throughout the journey, not just here. 


\section{Crossing the First Threshold / Committing to Change}

Physically, the protagonist commits to the journey by Crossing the Threshold into the Special World. By crossing physical barriers or undertaking new physical experiences, he relinquishes the physical complacency and routine of the Ordinary World and abandons all doubt as to whether a new world should be entered. His commitment to the journey is exemplified by a physical force that changes the course or intensity of the story, giving him the physical challenge of braving the new, unknown world. Upon entering the Special World, he knows that he has been bestowed with the chance to physically change or grow.

Emotionally, Crossing the First Threshold is a symbol of the protagonist's commitment to inner change, abandoning all doubt as to whether the journey should be undertaken. He commits to giving up his current emotional state, however negative or unfavourable that may be, and braves the unknown in the hope that he will be given the opportunity of emotional rebirth. Crossing into the Special World is a symbol of the protagonist giving up his ego, venturing forth for the sake of others, which will eventually result in him becoming a superior being; becoming heroic.

\section{Tests, Allies, Enemies / Experimenting with First Change}

Physically, the protagonist undertakes the course of the journey. His path is laden with physical tests, obstacles and the meeting of new people, and all of these become progressively difficult as the journey goes on. The Special World has a different look and feel to the Ordinary World, with different spaces, faces and rules. There are also different priorities in this world, for the protagonist and its inhabitants. The physical environment is therefore very alien, yet the protagonist does gradually become accustomed to it.

As the physical journey progresses, the protagonist's life literally or metaphorically faces danger; physical tests and obstacles have become so difficult that he comes 
head-to-head with dark, enemy forces. Nevertheless, he must remember that the physical tools provided by the Mentor will help him in some way.

Emotionally, the journey is laden with mental tests and obstacles. Meeting new people is challenging, but this gradually aids the protagonist's emotional transformation. By undertaking tests, overcoming obstacles and integrating with new people, then, he begins to understand the necessity of the journey to his learning of emotional lessons. He begins to dissolve, transcend or transmute the emotions of his past, now embracing the new ones that this world is allowing him to experience.

As the emotional journey progresses, the increasingly dangerous tests and obstacles stir up such a feeling that the protagonist's former emotional state is called into question. In a symbolic threat to life, he is forced to battle with himself and his deepest, darkest fears. Nevertheless, he must remember that the emotional tools provided by the Mentor will help him in some way.

\section{Approach to the Inmost Cave / Preparing for Big Change}

Physically, the protagonist is led into the Inmost Cave, a bleak place where he comes face-to-face with dark, enemy forces. High stakes reside in the Inmost Cave; physically, the protagonist has everything to lose. This moment of crisis physically

pushes him to his limits, forcing him to call upon the physical tools provided by the Mentor, and everything thus far acquired from the journey, in order to survive. It is in the Inmost Cave that the protagonist may experience physical rebirth, changing so much that he comes out of it a changed person. As such, the Approach to the Inmost Cave picks up the physical pace of the narrative, driving the audience's anticipation towards the Ordeal.

Emotionally, the Inmost Cave is a bleak place where the protagonist comes face-toface with his deepest, darkest fear. He believes that he will fail in his desire to undergo emotional transformation; he feels emotionally dead. This crisis tests the 
protagonist's emotional limits, and if he can come out of it having learned something about himself, he will experience emotional rebirth. Providing he has the will to do so, the emotional tools provided by the Mentor, along with the lessons learned on the journey, will help him to succeed when faced with the wrath of the Inmost Cave.

It is at this stage of the screenplay that the audience may notice a change of focus, between the protagonist's physical and emotional drive. So far, the protagonist has been driven by a physical want; the literal thing that he has been seeking. However, the Inmost Cave gives him an understanding of the real reason why the journey is being undertaken. As such, emotion may surface as the primary driving force of the screenplay from here on in: the need for emotional transformation.

\section{Ordeal / Attempting Big Change}

The Ordeal highlights the shift in focus from physical to emotional drive. Here, the protagonist understands the superior importance of emotional need over physical want.

Physically, the protagonist experiences a big change, from old self to new self. He goes from physically wounded to physically healed; physically lacking to physically fulfilled. The Ordeal puts him in direct confrontation with the darkest physical force he can imagine, and it is here that he must assess the physical possibilities available to him (no longer limitations) before deciding to move beyond the Inmost Cave. The Ordeal thus represents the death of the protagonist's physical past, with its physical problems and deficiencies, and from here on in we see the birth of his new physical future. The forces of the Inmost Cave challenge the protagonist to the hilt, but provided that he comes out alive he is set free and given the opportunity to attain the physical treasure he has been seeking.

Emotionally, old boundaries of the self are transcended during the Ordeal. The protagonist undergoes inner growth, from old self to new self. He goes from 
emotionally wounded to emotionally healed; emotionally lacking to emotionally fulfilled. He is put in direct confrontation with his own emotional darkness and, through experiencing this murky inner force, he finds atonement with himself. The protagonist thus experiences emotional affirmation: positioned within a physical encounter, his emotional past meets the emotional present, and through a process of fusion, becomes his emotional future. He thus submits to spiritual powers, understanding and conquering his emotional problem; and moving back towards the Ordinary World, he can guide and initiate those who follow his advice.

The Ordeal thus highlights the differences between the protagonist's physical and emotional journeys. It splits them apart in a narrative moment, emphasizes their individual fabric, and then rejoins them back into the whole. In this, we can see that the protagonist's emotional affirmation takes place within the containment of a physical scenario; yet, the physical scenario actually allows the emotional affirmation to take place. As such, the two journeys come into the Inmost Cave as one, momentarily divide in order to signify their individual focus, and then fuse back together to rejoin the developing narrative.

\section{Reward / Consequences of the Attempt (Improvements and Setbacks)}

Physically, in celebration of the journey travelled, the protagonist seizes the sword of victory and collects his Reward. The physicality of the gain is compensation for travelling the challenging terrain, from Crossing the First Threshold to leaving the Inmost Cave, and as such it gives the protagonist physical catharsis. The Reward itself is of a specific nature to the protagonist and his want, and in scale with the journey that he has travelled. Although his true reward may be emotional, he still craves this physical representation - an outward sign of his success. Having collected the Reward, he may now act, look or even speak differently. This is another physical sign of achievement, from the journey that he has not only travelled, but also survived. 
Emotionally, the Reward celebrates the journey travelled and compensates the emotional transformation that the protagonist has undergone. The reward is abstract and universal, appropriate in substance and in scale with the journey that he has travelled. Emotional transformation is understood by the protagonist as the superior Reward, but he still desires an outward sign of this so that others can share his achievement. Emotional transformation allows ascension to the Gods, where the protagonist becomes a heroic figure, with divine qualities. From here on, he may show different emotional attitudes towards people or problems, in direct contrast with those shown in the Ordinary World.

During this stage of the screenplay, the protagonist's physical Reward acts as an outward expression of his emotional transformation; yet, at the same time, emotional transformation requires physical expression. As such, the protagonist's emotional strength of being able to survive the Inmost Cave not only enables him to come out of it alive, but able to collect the Reward he initially came seeking.

\section{The Road Back / Rededication to Change}

Physically, the protagonist must leave the Special World and return to the Ordinary World. On the Road Back he overcomes further physical obstacles, and may even leave behind objects or people 'collected' from the journey. The protagonist may experience physical pursuit on his way back to the Ordinary World, but if so, he will be helped by the tools provided by the Mentor. Pursuit suggests that the protagonist may wish to remain in the Special World, but the physical environment can no longer accommodate him; so he must leave. The Road Back physically challenges and tests the protagonist, but his will to overcome further obstacles is evident. What previously seemed physically unachievable are now fully achievable, thanks to the physical transformation that he has undergone.

Emotionally, the protagonist feels a duty to return to the Ordinary World with the life-transmuting trophy that he can bestow upon others. Having a renewed sense of emotional balance, the overcoming of further obstacles is done with great emotional 
determination. Similarly, objects left behind in the Special World symbolize the emotional sacrifice to the world he is leaving. The Road Back emotionally challenges and tests the protagonist, but he is helped by the emotional tools given to him by the Mentor. The resolve of the protagonist is to implement the lessons learned on the journey to those in the Ordinary World. The Road Back thus represents a further shift in narrative focus, from physical want to emotional need; although the moment is physicalized through action, the drive is emotional. Subsequently, he feels that what previously seemed emotionally unachievable is now fully achievable, thanks to the emotional transformation that he has undergone.

\section{Resurrection / Final Attempt at Big Change}

Physically, the protagonist must demonstrate that he has changed, and that his change can benefit those living in the Ordinary World. As such, he may bring back a trophy from the Special World that he can show off, or use to great effect. However, it is important that the physicality of the Special World does not contaminate the Ordinary World, so he may be forced to make a sacrifice that shows him surrendering his old self and the physical journey he has travelled. A final physical test or hurdle may be set, seeking proof of the protagonist's true resurrection: a physical sign of his emotional transformation.

Emotionally, the protagonist must demonstrate that he has transformed, not just for himself but for the benefit of others. This is a symbolic moment of universal transformation, where the retaining of emotional over physical reward is important. As such, the emotional journey assumes superiority over the physical journey here, the protagonist proving that he has given up his personal limitations, as witnessed in the original Ordinary World. A difficult choice given to the protagonist tests his emotional strength, providing final proof that he truly has transformed. Sacrifice is thus significant for the Resurrection, where renouncing an old habit or attitude symbolizes the emotional transformation undergone. 


\section{Return with Elixir / Final Mastery of the Problem}

Physically, the protagonist is located firmly back in the Ordinary World, and perhaps even in the same scenario that the audience previously found him. The difference this time is that he has brought back physical treasure, and his emotional transformation is manifested through physical action or reaction. Revisiting a scenario from the original Ordinary World suggests that a journey has been travelled, and the bringing back of something physically new makes it different this time; the scenario is better. The very end of the screenplay may be punctuated by a physical representation of change, perhaps in the form of a visual image or a line of dialogue, giving final physical closure to the narrative.

Emotionally, the Return with Elixir demonstrates a reconciliation of the individual consciousness with the universal will. The protagonist returns to the original Ordinary World, but with a renewed state of emotion. He brings back emotional wisdom to heal others as well as himself, and because of the circular narrative form, a feeling is created that life will start again. Here is where an emotional punctuation mark is brought to the screenplay, the emotional journey superseding the physical journey. Physical action frames emotion, but emotion breaks the frame and takes on a life of its own. Nevertheless, both journeys work symbiotically to create one narrative: the screenplay whole.

\section{Reflecting upon the re-examined Hero's Journey}

The re-examined Hero's Journey enables the screenwriter to unpick the narrative stages of a screenplay and understand not only how action and emotion may feature in each, but also how the protagonist's emotional transformation is generated in direct relation to his undertaking of physical action. What is evident from the model, however, is that mapping both journeys is not as straightforward as it may seem. In many of the twelve stages, it is difficult to fully separate the two threads because they are interwoven, enjoying a symbiotic relationship where action is manifested physically, yet driven by emotion. What the re-examined Hero's Journey does offer, though, is an effective exploration of a screenplay's possible narrative, providing a deeper understanding of the fabric, form, 
function and relationship of physical action and emotion in a specific story template (which, admittedly, may suit some stories better than others).

As Luke Hockley (2007: 35) suggests:

Our sense of who we are and what we are doing is temporarily dissolved by, and into, the flow of cinematic images and sounds as viewers we are momentarily stitched into the story - sutured by, and into, the on-screen diegesis that is the momentarily believable world of the fiction film.

The word 'into' is key here: a screenwriter strives to stitch an audience into the story, desiring the audience to not merely view the story from a world that exists on the screen but to become part of it. The invisible hand of the screenwriter can physically guide an audience through an emotional journey, where action is used to manipulate feeling. The screenplay can thus generate such an emotional bond that an audience not only recognizes and reasons with the narrative situation, but assimilates it.

Cattrysse's aforementioned article, which explores how a consideration of audience involvement is crucial to a fuller understanding of a screenplay protagonist's 'want' and 'need': 'The next challenge will consist in turning those findings into workable writing tools' (Cattrysse 2009: 95). It is my hope that this article has provided working tools that may aid the screenwriter in the construction of a specific film narrative, emphasizing that screenplay narratives are best formed of two very different yet inherently connected threads that stem from 'want' and 'need' - the physical journey and the emotional journey - and that by understanding their fabric and function, a screenplay can be created in such a way to best connect an audience to the protagonist's emotional arc and the intent of the screenwriter. 


\section{References}

Aristotle (1996), Poetics (trans. Malcolm Heath), London: Penguin.

Aronson, L. (2001), Screenwriting Updated: New (and Conventional) Ways of Writing for the Screen, Los Angeles: Silman-James Press.

Batty, C. and Waldeback, Z. (2008), Writing for the Screen: Creative and Critical Approaches, Basingstoke: Palgrave Macmillan.

Campbell, J. (1993), The Hero with a Thousand Faces, London: Fontana.

Campbell, J. with Moyers, B. (1988), The Power of Myth, New York: Doubleday.

Cattrysse, P. (2009), 'The protagonist's dramatic goals, wants and needs', Journal of Screenwriting, 1: 1, pp. 83-97.

Clayton, S. (2007), 'Mythic structure in screenwriting', New Writing: The International Journal for the Practice and Theory of Creative Writing, 4: 3, pp. 208-223.

Egri, L. (2004), The Art of Dramatic Writing, New York: Simon and Schuster.

Field, S. (2003), The Definitive Guide to Screenwriting, London: Ebury Press.

Hall, S. (2006), 'Encoding/Decoding', in Meenakshi Gigi Durham and Douglas Kellner (eds), Media and Cultural Studies: Key Works, 2nd edn., Oxford: Wiley Blackwell, pp. 163-73.

Harper, G. (2006), 'Introduction', in Graeme Harper (ed.), Teaching Creative Writing, London: Continuum, pp. 1-7.

Hockley, L. (2007), Frames of Mind: A Post-Jungian Look at Cinema, Television and Technology, Bristol: Intellect.

Hutzler, L. (2005), ‘Reaching World-Wide Audiences’, ScriptWriter Magazine, 23, pp. 68.

McKee, R. (1999), Story: Substance, Structure, Style, and the Principles of Screenwriting, London: Methuen.

Moritz, C. (2001), Scriptwriting for the Screen, London: Routledge.

Vogler, C. (1999), The Writer's Journey: Mythic Structure for Storytellers and Screenwriters, 2nd edn., London: Pan Books. 
Voytilla, S. (1999), Myth and the Movies: Discovering the Mythic Structure of 50

Unforgettable Films, Studio City, CA: Michael Wiese.

\section{Contributor details}

Dr Craig Batty is a senior lecturer in screenwriting at Bournemouth University. He is a writer and script consultant, and has worked on various short film, feature film and television projects. He has written numerous articles and book chapters about screenwriting and media writing, and is the co-author of two books: Writing for the Screen: Creative and Critical Approaches and Media Writing: A Practical Introduction.

Contact: The Media School, Bournemouth University, 214 Weymouth House, Fern

Barrow, Poole. BH12 5BB

E-mail: cbatty@bournemouth.ac.uk

\footnotetext{
${ }^{\mathrm{i}}$ It is interesting to note here that most screenwriting texts only make reference to Aristotle, and occasionally, Campbell. These are perhaps 'safe' references in that their ideas are widely known throughout the humanities (English, film and media studies, for example), but also because these authors are deceased and are thus not writing competitive 'how to' books for the contemporary market.

ii 'Rightfully proposed' means an acknowledgement of what has come before, what problems have arisen and how this can be developed into new, more insightful knowledge.

iii This was one of the methodologies used in the critical commentary component to my practice-based Ph.D. in Screenwriting (awarded by Bangor University, July 2009).

iv These supplementary stages are: 'Belly of the Whale', 'Meeting with the Goddess', 'Woman as Temptress', 'Atonement with the Father', 'The Magic Flight', 'Rescue from Within', 'Crossing of the Return Threshold'. Vogler (1999: 12) maps these additional stages against his own for the reader in an easy-to-read table.
} 